\title{
Quality of life among patients with heart failure in tertiary care hospitals of Peshawar, KP, Pakistan; a cross-sectional study
}

\author{
Muhammad Iqbal', Bakhtyar Ali Shah², Dildar Muhammad ${ }^{3}$
}

\author{
Submitted: \\ October 17, 2020 \\ Accepted: \\ November 9, 2020 \\ Author Information \\ ${ }^{1-3}$ Institute of Nursing Sciences \\ Khyber Medical University Peshawar
}

\begin{abstract}
Introduction: Quality of life is a multifaceted concept which reflect a number of parameters including different symptoms. These factors are affected by many factors including age, gender, marital status, education levels and socioeconomic status. Quality of life in majority of patients with different medical conditions is significantly affected, however, little is known in patients with heart failure coming to tertiary care hospitals of Peshawar. This study was designed to assess quality of life among heart failure patients and to determine association between quality of life and selected demographic variables.

Material \& Methods: A cross-sectional study was conducted in three tertiary care hospitals; Lady Reading Hospital, Khyber Teaching Hospital and Hayatabad Medical Complex Peshawar. The data was collected through Minnesota Living with Heart Failure questionnaire. This questionnaire consists of twenty-one Likert's scale questions. Frequencies and percentages were calculated for categorical variables. All the Likert's scale questions were computed and mean and standard deviation were calculated. Independent t-test was applied to see mean difference across two categories of independent variables as male and female and ANOVA was applied to see the mean difference of quality of life across different categories including socioeconomic status. Chi square test was applied to see association between quality of life across different socio-demographic variables.

Results: The total number of participants included in this survey was 127 , whereas 67 (52.8\%) were males and $60(47.2 \%)$ were females. Majority of the participants $(52.8 \%)$ were of above 50 years of age followed by 40-50 years. A big proportion of the participants (66.1\%) was married. Majority of the participants (38.6\%) had an education level of matric or below followed by $20.5 \%$ and $22.5 \%$ intermediate and bachelors, respectively. Nearly half of the participants (44.1\%) had an income level from 10,000-20,000 rupees per month. An association of gender was observed with exacerbation of symptoms $(p=0.04)$, difficulty in climbing upstairs $(p<0.001)$, moving in the yard $(p<0.001)$, going outdoor $(p=0.036)$ and sleeping difficulty $(\mathrm{p}<0.001)$. Similarly, an association was of marital status was observed with sexual pattern $(\mathrm{p}=$ $0.037)$ and making you short of breath $(\mathrm{p}=0.002)$. Scores of quality of life across male and female gender was significantly different (male and female; $45.48 \pm 17.18$ and $53.82 \pm 16.55$ (mean \pm sd) respectively, $\mathrm{p}=0.006$ ). Conclusion: The study found that patients were deficient in knowledge regarding medical cardiac conditions and its symptoms. It is deemed important for the nurses to properly assess the level of knowledge of these patients and accordingly educate them so that they could better manage their condition at home.

Key Words: Exacerbation, Heart Failure, Nurse, Quality of Life, Severity of impairment, Shortness of Breath.
\end{abstract}

The authors declared no conflict of interest and agreed to be accountable for all aspects of the work in ensuring that questions related to the accuracy or integrity of any part of the work are appropriately investigated and resolved.All authors contributed substantially to the planning of research, questionnaire design, data collection, data analysis and write-up of the article as part of a student research team at Institute of Nursing Sciences Khyber Medical University Peshawar.The research work was supervised by Dr. Dildar Muhammad Assistant Professor Institute of Nursing Sciences Khyber Medical University Peshawar.

This article may be cited as: Iqbal M, Ali BA and Muhammad D. Quality of life among patients with heart failure in tertiary care hospitals of Peshawar, Khyber Pakhtunkhwa Pakistan; a cross-sectional study. Reh J Health Sci. 2020;2(2). 46-51

\section{INTRODUCTION}

Quality of life is in fact a complex concept which reflects a number of parameters including different symptoms like fatigue,

listlessness, difficulty in breathing, pain, and swelling and functional restraints. ${ }^{1}$ It is also variably affected by age, sex, marital status, education level, socioeconomic status, lifestyle habits such as smoking and drinking, personal views and events in life, wishes and hopes, and the harmony between daily life activities and desires. $^{2}$ The supportive caregiver, conducive features of environment and active involvement in a rehabilitation program may progress quality of life. ${ }^{3}$

Cardiovascular diseases are related with high morbidity, mortality and poor quality of life and cause a considerable economic burden. Heart failure is one of the major public health problems worldwide and its prevalence is increasing day by day. ${ }^{4}$ Cardiovascular diseases are the third leading cause of death in the United States. ${ }^{5}$ It is considered as one of the incapacitating diseases with poor prognosis across the globe. ${ }^{6}$ Around 2.8 million people suffer from heart failure in Pakistan. ${ }^{7}$ Approximately 23 million people are affected by heart failure all over the world and may further increase $25 \%$ by $2030 .{ }^{8}$ Studies revealed that in UK $3 \%$ of the people age 65 to 74 were being affected by heart failure. ${ }^{4}$ A study in Saudi Arabia showed that $20 \%$ of the patients admitted in hospitals with acute coronary heart disease were affected by heart failure. ${ }^{8}$ According to WHO the quality of life is the perception of an individual and his position in life in context of the culture and value systems in which he/she lives and in relation to his goals, expectations, standards and concerns. ${ }^{9}$ In addition, quality of life is the gap between actual and desired functions of a person. It has 
been reported that heart failure affects overall quality of life of patients and causes physical, psychological and socioeconomic problems to them. Sustaining a good quality of life is as much important as survival for most of the patients living with a chronic disease. ${ }^{10}$ Gender and marital status are considered to be associated with quality of life. In addition, gender and marital status had significant association with quality of life. Assessment of the QOL among heart failure patients is essential for nurses as they are involved in educating patients about their disease process, changes in behaviour, life style, activities and exercise, food intake and medications. ${ }^{11}$ There is plethora of international literature on the quality of life on health failure patients, however, little is reported in our local environment which demands for exploring this area.

\section{MATERIALS \& METHODS}

This was a cross-sectional study conducted in three public tertiary care hospitals of Peshawar Khyber Pakhtunkhwa; Lady Reading Hospital, Khyber Teaching Hospital and Hayatabad Medical Complex. The study was completed in six months period during the year 2018. Data were collected through a validated questionnairre. Sample size was calculated through Raosoft software as 127 patients. Consecutive sampling technique was used for selecting the study subjects. Patients who were 18 years old or above, diagnosed with heart failure 6 months prior to the study, were included in the survey. Permission to carry out this survey was taken from respective hospitals' directors. Informed consent was taken from the study subjects. Data were analysed through
SPSS version 22. Frequencies and percentages were calculated for categorical variables whereas means and standard deviations were calculated for continuous variables. Independent sample t-test was applied to see the differences across the two categorical variables whereas ANOVA was applied for the mean differences across multiple categories. Chi-square test was applied to see an association between categorical variables keeping the level of significance at 0.05 .

\section{RESULTS}

\section{Demographic variables affecting quality of life of patients with Heart Failure}

The total participants who met the inclusion criteria were 127 including 67 (52.8\%) male and 60 (47.2\%) female. Majority of the participants were above 50 years (29.1\%) followed by $40-50$ years (23.6\%) and 30-40 years (18.1\%). Majority of the participants were married $(66.1 \%)$ and the rest were single (33.9\%). Regarding family structure, the participants from nuclear family were $41.7 \%$ and participants from extended family were $10.2 \%$ and participants from joint family system were $48 \%$. Majority of the participants (38.6\%) were having education level of matric or below followed by bachelor (22.8\%), Intermediate (20.5\%), and master (1.6\%). A small number, $16.5 \%$ participants, were not educated at all. In part of monthly income, the maximum number of the participants (44.1\%) were having an income level in the category of 10,000-20,000 rupees per month. In other categories such as $20,000-30,000$, the proportion of participants was $26 \%$ and those in the category of $30,000-40000$ were only $19.7 \%$ (table 1 ).

Table 1: Demographic details of the participants

\begin{tabular}{llll}
\hline Variables & Categories & Frequencies & Percentages \\
\hline \multirow{2}{*}{ Gender } & Male & 60 & 47.2 \\
& Female & 67 & 52.8 \\
Age in years & $20-30$ & 37 & 2.1 \\
& $30-40$ & 30 & 18.1 \\
Marital Status & $40-50$ & 23 & 23.6 \\
& Above 50 & 37 & 29.1 \\
Family Structure & Single & 43 & 33.9 \\
& Married & 84 & 66.1 \\
& Nuclear & 53 & 41.7 \\
Extended & 13 & 10.2 \\
Level of education & Joint & 61 & 48 \\
& Illiterate & 21 & 16.5 \\
& Matric or below & 49 & 38.6 \\
& Intermediate & 26 & 20.5 \\
& Bachelor & 29 & 22.8 \\
& Master or above & 2 & 1.6 \\
Monthly Income & 10k-20k & 56 & 44.1 \\
& 20k-30k & 33 & 26.0 \\
& 30k-40k & 25 & 19.7 \\
& $40 \mathrm{k}-50 \mathrm{k}$ & 10 & 7.9 \\
& Above $50 \mathrm{k}$ & 3 & 2.4 \\
\hline
\end{tabular}


Quality of Life in Patients with Heart Failure

Parameters related to quality of life are reported on a validated questionnaire scored on Likert Scale as, No, Very Little, Little,
Little more, More, Much, and Very Much. The detailed description and frequency distribution table- 2 has been given.

Table-2 parameters related to QOL with heart failure

\begin{tabular}{|c|c|c|c|c|c|c|}
\hline $\begin{array}{l}\text { Did your heart failure prevent you from living as } \\
\text { you wanted during the past month ( } 4 \text { weeks) }\end{array}$ & z & 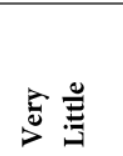 & 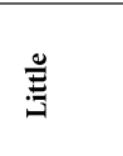 & 莺 & $\stackrel{\tilde{g}}{\mathrm{~g}}$ & 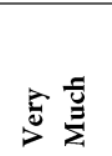 \\
\hline & $f(\%)$ & $f(\%)$ & $f(\%)$ & $f(\%)$ & $f(\%)$ & $f(\%)$ \\
\hline Causing swelling in your ankles or legs? & $45(35.4)$ & $44(34.6)$ & $21(16.5)$ & $7(5.5)$ & $5(3.9)$ & $5(3.9)$ \\
\hline Making you sit or lie down to rest during the day? & $20(15.7)$ & $16(12.6)$ & $50(39.4)$ & $21(16.5)$ & $11(8.7)$ & $9(7.1)$ \\
\hline $\begin{array}{l}\text { Making you walk about or climbing stairs } \\
\text { difficult? }\end{array}$ & $12(9.4)$ & $22(17.3)$ & 2116.5) & $34(26.8)$ & $10(7.9)$ & $28(22)$ \\
\hline $\begin{array}{l}\text { Making you work around the house or yard } \\
\text { difficult? }\end{array}$ & $7(5.5)$ & $26(20.5)$ & $35(27.6)$ & $17(13.4)$ & $32(25.2)$ & $10(7.9)$ \\
\hline Making you go away from home difficult? & $9(7.1)$ & 24(18.9) & $30(23.6)$ & $28(22)$ & $18(14)$ & $18(14)$ \\
\hline Making your sleeping well at night difficult? & $26(20.5)$ & $17(13.4)$ & $27(21.3)$ & $19(15)$ & $16(12.6)$ & $22(17.3)$ \\
\hline $\begin{array}{l}\text { Making relating to or doing things with your } \\
\text { friends or family difficult? }\end{array}$ & $21(16.5)$ & $20(15.7)$ & $40(31.5)$ & $23(18.1)$ & $12(9.4)$ & $11(8.7)$ \\
\hline Making you earn living difficult? & $7(5.5)$ & $19(15)$ & $38(29.9)$ & $27(21.3)$ & $18(14.2$ & $18(14.2)$ \\
\hline $\begin{array}{l}\text { Making your recreational pastimes, sports or } \\
\text { hobbies difficult? }\end{array}$ & $22(17.3)$ & $18(14.2)$ & $23(18.1)$ & $26(20.5)$ & $17(13.4)$ & $21(16.5)$ \\
\hline Making your sexual activities difficult? & $26(20.5)$ & $17(13.4)$ & $19(15)$ & $24(18.9)$ & $20(15.7)$ & $21(16.5)$ \\
\hline Making you eat less of the foods you like? & $21(16.5)$ & $18(14.2)$ & $34(26.8)$ & 24(18.9) & $18(14.2)$ & $12(9.4)$ \\
\hline Making you short of breath? & $19(15.1)$ & $15(11.8)$ & $30(23.6)$ & $20(15.7)$ & $24(18.9)$ & $19(15)$ \\
\hline Making you tired, fatigued, or low on energy? & $14(11)$ & $17(13.4)$ & $22(17.3)$ & 25(19.7) & 24(18.9) & $25(19.7)$ \\
\hline Making you stay in a hospital? & $16(12.6)$ & $25(19.7)$ & 24(18.9) & $29(22.8)$ & $22(17.3)$ & $11(8.7)$ \\
\hline Costing you money for medical care? & 15(11.8) & $20(15.7)$ & $32(25.2)$ & 25(19.7) & $29(22.8)$ & $6(4.7)$ \\
\hline Giving you side effects from treatments? & $38(29.9)$ & $13(10.2)$ & $21(16.5)$ & $38(29.9)$ & $8(6.3)$ & $9(7.1)$ \\
\hline $\begin{array}{l}\text { Making you feel you are a burden to your family } \\
\text { or friends? }\end{array}$ & $23(18.1)$ & $16(12.6)$ & $44(34.6)$ & $19(15)$ & $15(11.8)$ & $10(7.9)$ \\
\hline Making you feel loss of self-control in your life? & $20(15.7)$ & $32(25.2)$ & $28(22)$ & $18(14.2)$ & $16(12.6)$ & $13(10.2)$ \\
\hline Making you worry? & $15(11.8)$ & $20(15.7)$ & $32(25.2)$ & $30(23.6)$ & $18(14.2)$ & $12(9.4)$ \\
\hline $\begin{array}{l}\text { Making it difficult for you to concentrate or } \\
\text { remember things? }\end{array}$ & $23(18.1)$ & $20(15.7)$ & 25(19.7) & $18(14.2)$ & $24(18.9)$ & $17(13.4)$ \\
\hline Making you feel depressed? & $18(14.2)$ & $17(13.4)$ & $27(21.3)$ & $20(15.7)$ & $20(15.7)$ & $25(19.7)$ \\
\hline
\end{tabular}


The point whether the heart failure makes the patient sit or lie

down to take rest during the day, $39.4 \%$ said yes for little and $8.7 \%$

responded in very much. Similarly, whether the patients have

remained restricted from recreational activities, $20.5 \%$ responded in little more; means they are not able to fully enjoy recreational activities. All the points along with frequencies and percentages are given in table- 2 .

Table 3: Association between gender and quality of life

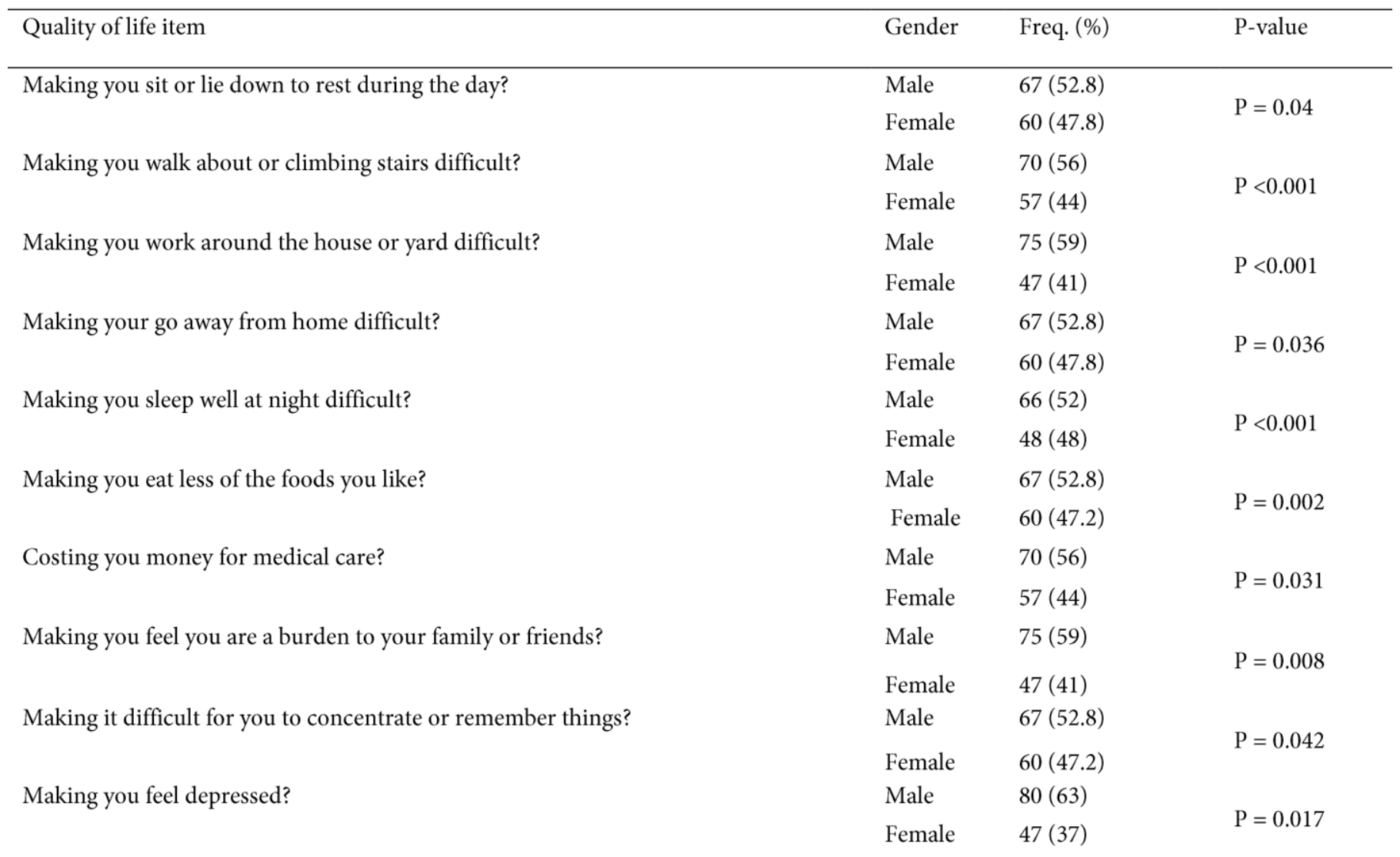

Chi-square test and fisher's exact test were applied to see whether association exists between the different items of quality of life and the socio-demographic variables. The outcome of the fisher's exact test shows that there was an association between the exacerbation of symptoms regarding up and about activities and gender ( $\mathrm{p}=$ $0.04)$. Similarly, an association was found between gender and climbing stairs $(\mathrm{p}<0.001)$ and gender and going outside home ( $\mathrm{p}$
$<0.036)$. In-house activities were found to have an association with gender $(\mathrm{p}<0.001)$. Sleeping difficulty at night and gender were found to be associated ( $p<0.001$ ). Difficulty in sleeping at night was found different across males and females which was found more in males than females. Feeling oneself as burden on family and friend was found to be associated with gender $(\mathrm{p}=0.008)$.

Table 4: Association between marital status and quality of life

\begin{tabular}{|c|c|c|c|}
\hline Likert's point & Frequency $(9$ & & p-value \\
\hline Making your sexuality activity difficult. & $\begin{array}{l}\text { Married } \\
\text { Unmarried }\end{array}$ & $\begin{array}{l}88(69.3) \\
39(30.7)\end{array}$ & 0.037 \\
\hline Making you eat less of the food you like. & $\begin{array}{l}\text { Married } \\
\text { Unmarried }\end{array}$ & $\begin{array}{l}40(30) \\
87(70)\end{array}$ & 0.048 \\
\hline Making you short of breath & $\begin{array}{l}\text { Married } \\
\text { Unmarried }\end{array}$ & $\begin{array}{l}70(55) \\
57(45)\end{array}$ & 0.002 \\
\hline Costing you money for medical acre. & $\begin{array}{l}\text { Married } \\
\text { Unmarried }\end{array}$ & $\begin{array}{l}80(62.9) \\
47(37.1)\end{array}$ & 0.009 \\
\hline
\end{tabular}


The outcome of chi-square and Fisher's exact tests shows that marital status and some of the Likert's scale point were found to be associated with marital status. Sexuality was found to be associated ( $p=0.037)$. Similarly, choice of food and marital status was found to be statistically associated ( $p=0.048$ ). Likewise, there was an association between shortness of breath and marital status ( $\mathrm{p}=$ $0.002)$.

When the total points regarding quality of life were computed through SPSS and converted to continuous variable, Independent sample T-Test was applied to see the mean difference across the gender. There was a significant difference across the gender (male mean scores $=45.48$ and female mean scores $=53.82, \mathrm{p}=0.006$ ). The mean score of all the likert's scale points was calculated and then compared across the marital status. This was also found to be statistically significant (married mean score $=43.9$ \& unmarried mean score $=51.9, \mathrm{p}=0.016$ ).

The output of ANOVA test showed that the mean score of Likert points was found to be statistically different across the different age groups ( $\mathrm{p}<0.001$ ). Tukey HSD post hoc test further shows that the mean of age group 50 years and above was found different from age group 20-30 years. Similarly mean score of age group 30-40 was different from age group 50 years and above.

When the mean score was compared across the means of family structures, it was found statistically significant $(p=0.012)$. Post hoc test was applied for further analysis and it was found from the outcome that mean score of extended family was different from the other two-family structures that is nuclear and joint.

\section{DISCUSSION}

Quality of life in heart failure patients is perception of the effects of heart failure on life of the patients. This study was carried out on a cohort of 127 patients who were hospitalized for heart failure in different hospitals of Peshawar. The data were collected through an adopted questionnaire, 'The Minnesota Living with Heart Failure Questionnaire (MLHFQ)'. ${ }^{12}$ This study also supports and validates the MLHFQ for its validity and reliability. In this study, the quality of life of the heart failure patients was measured; and, association between quality of life with selected demographic variables using Minnesota Questionnaire was determined.

The study has proved that demographic variables has a significant association with QOL. Women's QOL is severely affected by heart failure compared to their counterpart's male population. Another study conducted on 6700 patients on the same subject also supports the current study results that in patients with heart failure, $70 \%$ of the patients were female. ${ }^{12}$ In relation to the Quality of Life, female patients were found more depressed compared to their counterpart's male population. The relative better quality of life in men may be due to the fact that men have more physical and mental strength compared to women in general. The findings of this study show that marital status has a significant impact on the QOL of the heart failure patients. It has been noted that unmarried patients live poor quality of life compared to married patients. This is because married patients have relatively more social and emotional support. Results of our study show that those patients who live in joint family have better QOL compared to those in nuclear family because of extensive social and psychological support. ${ }^{13}$ Statistics of our study show that socioeconomic factors have also a significant association with
QOL in heart failure patients. The next hypothesis of our study was to explore whether quality of life is associated with literacy rate of the patients. QOL was found to be poorer in those who were illiterate and were unaware of the disease process. Education helps the patients to adopt themselves to fight with the disease and its consequences. A similar study also supports the findings of our study that low literacy level of patients associated with worse heart failure quality of life. ${ }^{15}$

\section{CONCLUSION}

The findings of this study show that quality of life of the heart failure patients is seriously affected by heart failure. The study shows that heart failure has affected all dimensions of life of the patients including their physical and emotional QOL. Therefore, nurses should be aware of the heart failure patient's physical and psychological symptoms to apply appropriate interventions to improve their QOL. The findings of this study also show that QOL in patients with heart failure is influenced by demographic, social and economic factors including gender, age, marital status, education and economic status.

\section{LIMITATIONS}

This study was conducted in only three public sector hospitals in Peshawar with a sample size of 127 patients. The study findings may not be generalized to whole Pakistan due to its small sample size. However, this study was the first in its nature from Pakistani context as the researcher couldn't find any published study on the same topic from the local context. The study, therefore, may provide base line findings for further research work in this area.

\section{RECOMMENDATIONS}

This study indicates that quality of life is multi-dimensional which is drastically affected by many reasons in patients with heart failure. In these domains physical, mental, psychological, environmental, social, economic, and educational factors are included. Appropriate measures should be taken to ascertain the stressors in multi-dimensional domain and appropriate interventions should be taken to improve the quality of life in patients with heart failure.

Nurses and health care professionals should give discharge teaching to patients with heart failure for maintaining optimal quality of life in community. There should be a mechanism for proper follow up of patients in community on regular basis. Nurses with specialist knowledge and skills shall be deployed in cardiac set ups across the country to educate heart failure patients and their families.

Nursing curriculum shall include contents on maintaining quality of life among heart failure patients. Nurses shall be prepared at master level with specialist knowledge and practice to care for cardiac patients. Since this study utilized cross-sectional design, to determine association among variables and its strength cohort/follow up studies may be conducted. For gaining an in depth understanding of the challenges and issues faced by HF patients in community qualitative exploratory studies may be conducted. A multidisciplinary approach shall be used to tackle the multiple issues faced by HF patients in community. Hospital administrators may design special education pamphlets/leaflets for 


\section{REFERENCES}

1. Olsen SL, Gilbert EM, Renlund DG, Taylor DO, Yanowitz FD, Bristow MR. Carvedilol improves left ventricular function and symptoms in chronic heart failure: A double-blind randomized study. J Am Coll Cardiol. 1995 May 1;25(6):1225-31.

2. Dunderdale $\mathrm{K}$, Thompson DR, Beer SF, Furze G, Miles JNV. Development and Validation of a Patient-Centered HealthRelated Quality-of-life Measure: The Chronic Heart Failure Assessment Tool. J Cardiovasc Nurs. 2008 Aug;23(4):364.

3. Iqbal J, Francis L, Reid J, Murray S, Denvir M. Quality of life in patients with chronic heart failure and their carers: a 3-year follow-up study assessing hospitalization and mortality. Eur J Heart Fail. 2010;12(9):1002-8.

4. AbuRuz ME, Alaloul F, Saifan A, Masa'Deh R, Abusalem S. Quality of Life for Saudi Patients With Heart Failure: A CrossSectional Correlational Study. Glob J Health Sci. 2016 Mar;8(3):49-58.

5. Sawafta FJS. Quality of Life of Chinese Heart Failure Patients and Their Family Caregivers. 2013;3(2):12.

6. EVALUATION OF DEPRESSION IN P A T I E N T S U N D E R O I N G CHEMOTHERAPY. Health Sci J. 2008;2(3):11.

7. HEART FAILURE IN PAKISTAN: A Demographic Survey - Journal of Cardiac Failure [Internet]. [cited 2019 Jan 19]. A v a i a b l e f ro m : https://www.onlinejcf.com/article/S10719164(06)00946-8/abstract
8. AbuRuz ME, Alaloul F, Saifan A, Masa'Deh R, Abusalem S. Quality of Life for Saudi Patients With Heart Failure: A CrossSectional Correlational Study. Glob J Health Sci. 2016 Mar;8(3):49-58.

9. Adebayo. Quality of life in heart failure: A review [Internet]. [cited 2019 Jan 15]. A v a i l a b I e f $\quad$ o m http://www.nigjcardiol.org/article.asp?issn $\begin{array}{lcccc}= & 0 & 1 & 8 & 9 \\ 7969 ; \text { year }=2017 ; \text { volume }=14 ; \text { issue }=1 \text {;spag }\end{array}$ $\mathrm{e}=1$;epage $=8$; aulast $=$ Adebayo

10. The effect of CardioNet hom telemonitoring for congestive heart failure patients: An observational research study ProQuest [Internet]. [cited 2019 Jan 15] A v a i l a b I e f $\mathrm{r}$ o m : https://search.proquest.com/openview/84 bc341b962a2fce674aaa3e5e6f7e32/1?pqorigsite $=$ gscholar $\& \mathrm{cbl}=18750 \&$ diss $=y$

11. Quality of Life in Cardiovascular Patients in Iran and Factors Affecting It: A Systematic Review [Internet]. [cited 2019 Jan 15]. A v a i l a b I e f $r \circ \mathrm{m}$ https://www.ncbi.nlm.nih.gov/pmc/articles /PMC3825371/

12. Masoudi FA, Havranek EP, Smith G, Fish RH, Steiner JF, Ordin DL, et al. Gender, age, and heart failure with preserved left ventricular systolic function. J Am Coll Cardiol. 2003 Jan 15;41(2):217-23.

13. Linking Clinical Variables With HealthRelated Quality of Life: A Conceptual Model of Patient Outcomes I JAMA I JAMA Network [Internet]. [cited 2019 Jan 17]. A v a i l a b I e fro m https://jamanetwork.com/journals/jama/art icle-abstract/385444

14. Luttik ML, Jaarsma $T$, Veeger $N$, van Veldhuisen DJ. Marital status, quality of life, and clinical outcome in patients with heart failure. Heart Lung. 2006 Jan 1;35(1):3-8.

15. Macabasco-O'Connell A, DeWalt DA, Broucksou KA, Hawk V, Baker DW, Schillinger D, et al. Relationship Between Literacy, Knowledge, Self-Care Behaviors, and Heart Failure-Related Quality of Life Among Patients With Heart Failure. J Gen Intern Med. 2011 Sep 1;26(9):979-86. 